\title{
XENON in medical area: emphasis on neuroprotection in hypoxia and anesthesia
}

\author{
Ecem Esencan ${ }^{1}$, Simge Yuksel ${ }^{1}$, Yusuf Berk Tosun ${ }^{1}$, Alexander Robinot ${ }^{2}$, Ihsan Solaroglu ${ }^{1}$ and John H Zhang $^{3 *}$
}

\begin{abstract}
Xenon is a medical gas capable of establishing neuroprotection, inducing anesthesia as well as serving in modern laser technology and nuclear medicine as a contrast agent. In spite of its high cost, its lack of side effects, safe cardiovascular and organoprotective profile and effective neuroprotective role after hypoxic-ischemic injury (HI) favor its applications in clinics. Xenon performs its anesthetic and neuroprotective functions through binding to glycine site of glutamatergic N-methyl-D-aspartate (NMDA) receptor competitively and blocking it. This blockage inhibits the overstimulation of NMDA receptors, thus preventing their following downstream calcium accumulating cascades. Xenon is also used in combination therapies together with hypothermia or sevoflurane. The neuroprotective effects of xenon and hypothermia cooperate synergistically whether they are applied synchronously or asynchronously. Distinguishing properties of Xenon promise for innovations in medical gas field once further studies are fulfilled and Xenon's high cost is overcome.
\end{abstract}

Keywords: Xenon, Hypoxia, Ischemia, Neuroprotection, Anesthesia, Hypothermia, NMDA

\section{Introduction}

Medical gases have a wide scope of applications in medical area. In the field of medicine, medical gases are used for many practices such as anesthesiology, hyperbaric oxygen therapy, neuroprotection and hypothermia [1]. For instance, hydrogen, the first element in periodic table, is a medical gas that is synthesized in fermentation of non-digestible carbohydrates in human cells [1-3], has a neuroprotective role following middle cerebral artery occlusion (MCAO) [4], neonatal HI [5,6] and newborn pig asphyxia models [1,7]. Helium which has the second highest prevalence in the universe [1] has therapeutic effects on arrthymia [8] and inflammation $[9,10]$, and has myocardioprotective role [1,11]. Argon, another noble gas has been used as anesthetic and neuroprotective agent [12]. Xenon which is a medical trace gas in Earth's atmosphere [13] is proven to be effective in the fields of anesthesia and neuroprotection [12] (Figure 1).

In vitro and in vivo studies prove that Xenon has therapeutic effects on various neurodegenerative outcomes. Due to these promising results, in this paper we

\footnotetext{
* Correspondence: johnzhang3910@yahoo.com

${ }^{3}$ Departments of Neurosurgery and Physiology, Loma Linda University, Loma Linda, CA, USA

Full list of author information is available at the end of the article
}

aimed to review the beneficial applications of Xenon in clinical aspects mainly for neuroprotection as well as anesthesia.

\section{Discovery and chemical properties of xenon}

In 1898, Sir William Ramsay who was a Professor of Chemistry at University College London discovered Xenon. Ramsay, a Noble prizewinner for the discovery of krypton and neon, also found Xenon with his student Morris Travers in the residue of evaporating components of liquid air $[14,15]$. Today, Xenon is still purified by fractional distillation of liquefied air; similar to the method Ramsay had performed [15]. With his findings, Ramsay estimated that Xenon was found in 1 part in 20 million in Earth's atmosphere [14]. Recent studies prove the occurrence of Xenon that Ramsay had estimated [15].

After Xenon's discovery in 1898, Albert R. Behnke Jr. used different breathing mixtures including Xenon in his studies of exploring the drunkenness in deep sea divers [16]. He concluded that Xenon could be used as an anesthetizing agent with the results obtained from his trials in 1939. Following this outcome, Xenon was used as a surgical anesthetic agent for the first time by Stuart C. Cullen and Gross in 1951 [16,17]. It was selected to be an effective anesthetic with its low blood-gas partition coefficient 


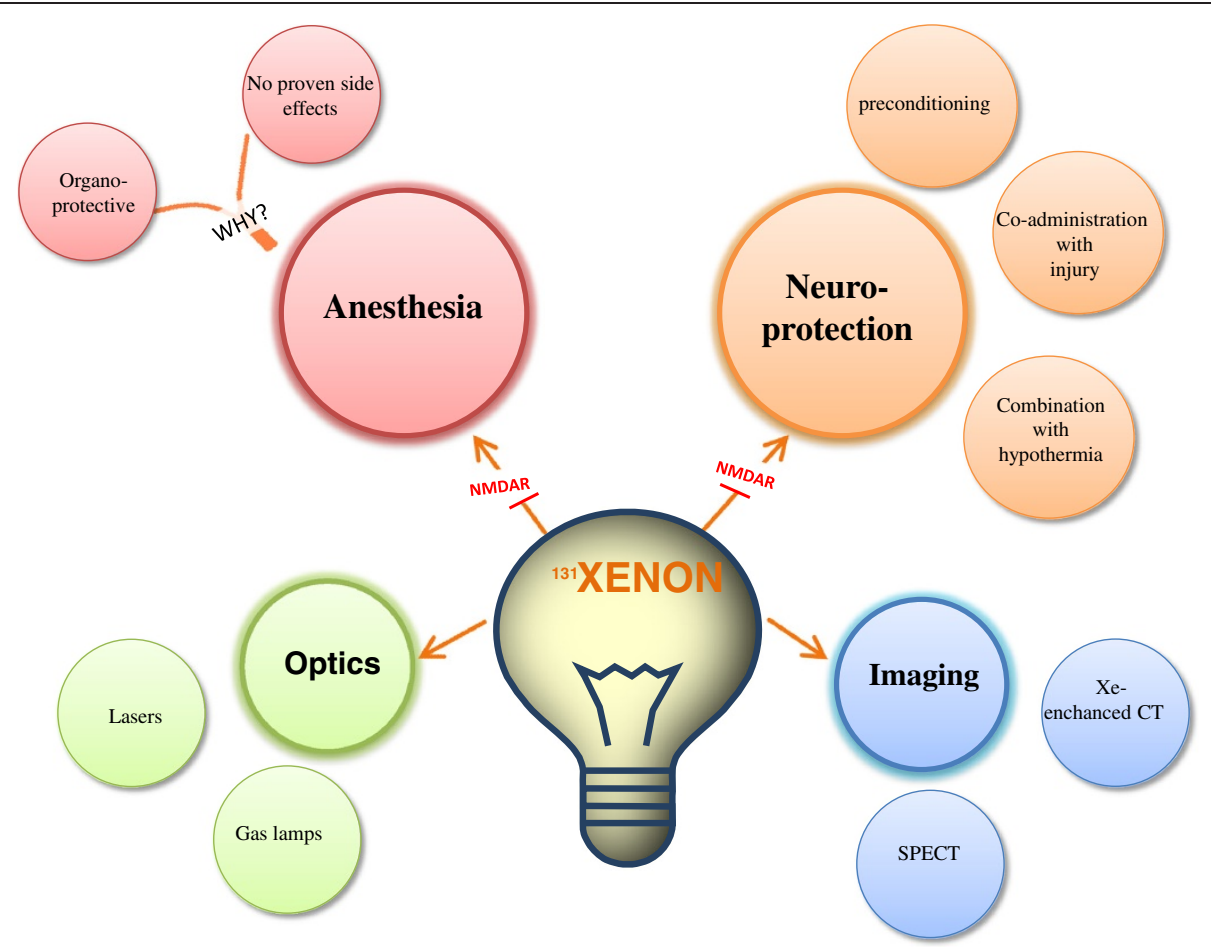

Figure 1 Schema Summarizing Xenon's applications: Noble gas xenon is used in various fields. In medicine, Xenon can be utilized as a neuroprotective and anesthetic agent. It can also be used as a contrast agent in imaging. Plus it has the potential to be used in the field of optics.

(0.115) $[14,18,19]$, safe cardiovascular profile [17] and ability to penetrate through blood brain barrier without extensive effort $[14,17,18]$. These advantageous properties enable Xenon to have a rapid induction, which is a key element in anesthesia [1,17]. Therefore, among the first five noble gases in the periodic table that are helium, neon, argon, krypton and Xenon, Xenon is the most potent in anesthesia [20]. Moreover, Xenon is nonteratogenic [14] and non-fetotoxic [15,21]. Hence, it is a good interest for research with its possible neuroprotective and anesthetic properties.

Xenon is a colorless, heavy and odorless noble gas [1]. Having the chemical properties of noble gases, Xenon cannot form covalent bonds with other molecules. However, it can still have binding action via van der Waals forces. These forces occur in instantaneously polarized atoms. This can be the only mechanism of binding, since noble gases are non-polar and uncharged. Spontaneous polarization enables the formation of a charged binding site of the atom so that it can attract surrounding molecules. In Xenon's case, spontaneous polarization of Xenon helps it bind the active sites of enzymes and receptors by interfering with amino acids $[12,22]$. Thanks to its high number of electrons and lowerbinding energy, Xenon's ability to be polarized is greatest among other noble gases [12].

\section{Neuroprotective role of xenon}

Cardiac arrest (CA) is one of the major causes of death in both United States and Europe [23,24]. Although with advanced and adventitious cardiopulmonary resuscitation systems, almost $50 \%$ of CA victims are saved $[25,26]$, the next threat for resuscitated patients is global cerebral hypoxia-ischemia $[27,28]$. It increases the mortality after sudden CA with the mechanism of necrosis or apoptosis of neuronal tissue [29-31]. Cognitive dysfunction, a permanent or transient inability to perform daily activities $[32,33]$ is an expected result, especially due to hippocampal injury [34-36].

Another major risk group that is affected by hypoxiaischemia is neonates, because of the devastating nature of labor procedure. Up to 1-2/1000 live births result in severe hypoxia-ischemia and $60-70 \%$ of the ones suffering from hypoxia-ischemia may die or suffers life-long disabilities [37]. The risk of having hypoxia-ischemia after $\mathrm{CA}$ or in perinatal period cannot be anticipated but should be scrutinized. Since the risk of having hypoxia-ischemia is unpredictable, it is unlikely to develop a method to be administered prior to insult [19]. Consequently, a therapeutic strategy or a neuroprotective agent should be evolved to manage and limit the effects of hypoxia-ischemia after it eventuates [17]. 


\section{In-vivo studies}

Recent in vivo studies on sub-anesthetic dosage of Xenon with $50 \%$ concentration had promising results against neonatal hypoxia-ischemia [1], CA induced cerebral ischemia [36] and neurobehavioral dysfunction caused by brain insult [38]. Major mechanisms lying behind Xenon's neuroprotective property are the reduction of ischemia-induced neurotransmitter release [39] as well as the antagonistic property against NMDA receptors $[36,37,40]$ (Figure 2). It has been proven by Franks and his colleagues that Xenon's property of being antagonist to NMDA receptors is a key factor [41], since NMDA receptors are primarily involved in initiation and progression of apoptosis in neural tissue $[19,42]$. Fries et al. state that after Xenon treatment, there was a reduction of perivascular inflammation in putamen and caudate nucleus on pigs with post CA [36]. In addition, Dingley et al. showed short-term neuroprotective effects of Xenon administration in neonatal rats which were exposed to hypoxia-ischemia [1,43]. Also, it was demonstrated that preconditioning of Xenon displays neuroprotective effects like reducing the size of infarction and enhancing neurological functions in neonatal rats having hypoxia-ischemia $[1,44]$. It has also been indicated that Xenon has a higher efficacy in cortex rather than subcortex due to the difference in vascularity and in density of NMDA receptors in two distinct layers of cerebrum [45].

Another beneficial property of Xenon is its non-toxic chemical characteristic which enables the usage of the gas on neonates. The high risk of any traumatic event during childbirth brings the idea of Xenon preconditioning to mother as a method of reducing the possibility of brain insult to the neonate [46]. Xenon is an ideal gas for this model with its cardiovascular stability [47] and myocardial protection property [48], as well as its rapid induction rate through blood-brain-barrier [14,49]. As a

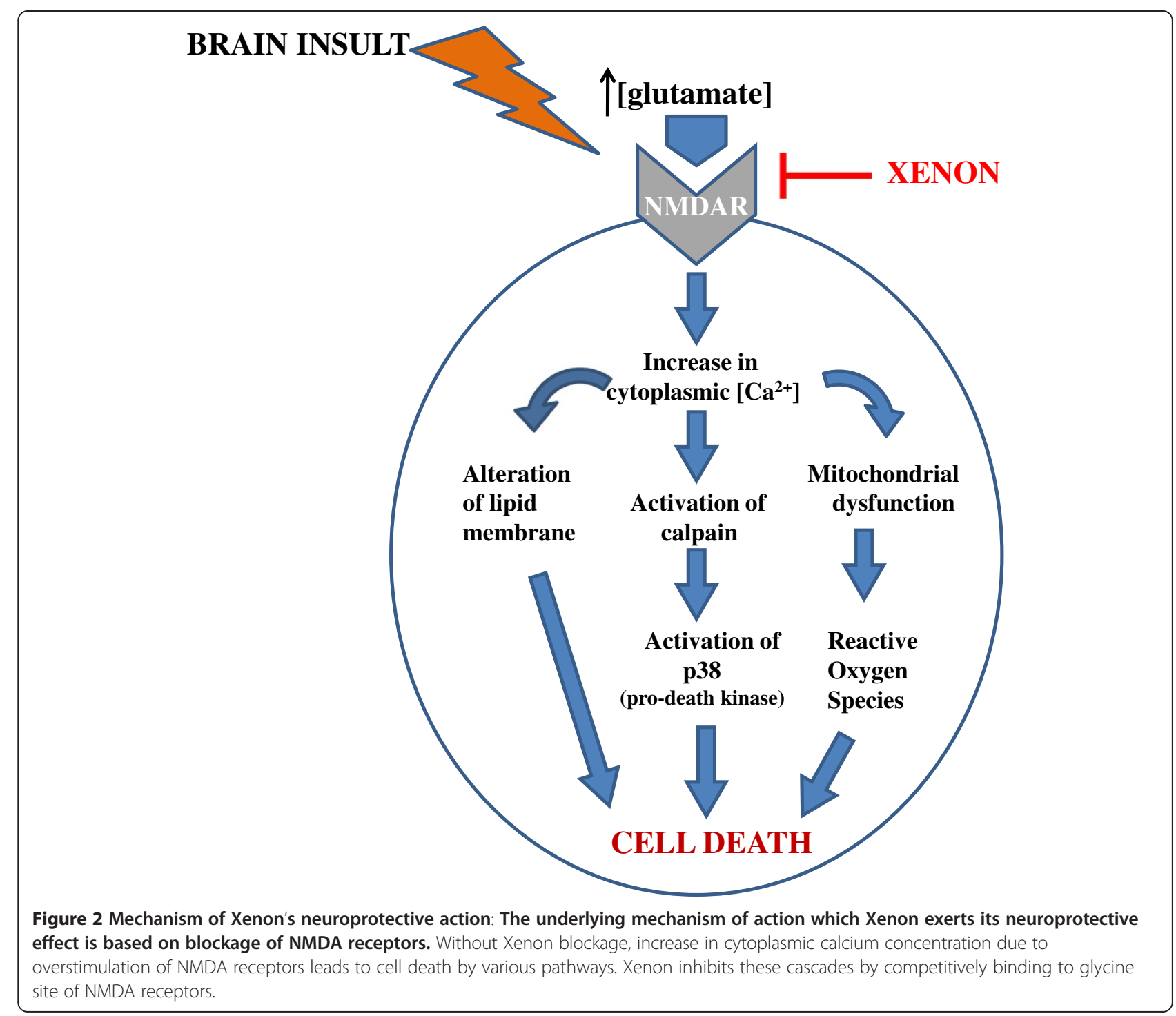




\section{Table 1 In-vivo and in-vitro models demonstrating the neuroprotective effects of Xenon}

\begin{tabular}{|c|c|c|c|}
\hline Reference & Model & Intervention & Results \\
\hline Bantel et al., 2009 & Neuronal damage due to OGD & Preconditioning with $75 \%$ Xenon for 2 hours & $\begin{array}{l}\text { Xenon preconditioning reduces neuronal injury through activation of } \\
\text { plasmalemmal ATP sensitive potassium channel [62] }\end{array}$ \\
\hline $\begin{array}{l}\text { Liu et al, } 2011 \\
\text { Wilhelm et al, } 2002\end{array}$ & Neuronal damage due to OGD & Xenon saturated medium for 24 hours (in vitro) & $\begin{array}{l}\text { Reduction in lactate dehydrogenase release proves that Xenon reduces } O G D \\
\text { induced neuronal cell death at subanesthetic concentrations }[1,61] \text {. }\end{array}$ \\
\hline Homi et al, 2003 & MCAO in mice & $\begin{array}{l}\text { 70\%, 35\% Xenon during middle cerebral artery } \\
\text { occlusion for } 1 \text { hour }\end{array}$ & $\begin{array}{l}\text { Application of Xenon during MCAO reduces total infarct size and augments } \\
\text { neurologic outcome [54]. }\end{array}$ \\
\hline Horiguchi et al, 2006 & MCAO in mice & Preconditioning with $70 \%$ xenon for 2 hours & $\begin{array}{l}\text { Xenon preconditioning induces neuroprotection in mice model of } \\
\text { middle cerebral artery occlusion [64]. }\end{array}$ \\
\hline Hobbs et al, 2008 & Neonatal HI & $\begin{array}{l}\text { Hypothermia }\left(32^{\circ} \mathrm{C}\right) \text { with inhalation of } \\
50 \% \text { Xenon for } 3 \text { hours }\end{array}$ & $\begin{array}{l}\text { Combination of hypothermia and Xenon increases neuroprotection from } \\
37 \% \text { (hypothermia only) to } 76 \% \text { [70]. }\end{array}$ \\
\hline Martin et al, 2007 & Neonatal HI & $\begin{array}{l}\text { Asynchronous application of Xenon } \\
(20 \%) \text { and hypothermia }\left(35^{\circ} \mathrm{C}\right) \text { with } 1 \text { hour and } \\
5 \text { hours gap in between the treatments }\end{array}$ & $\begin{array}{l}\text { Asynchronous combination of Xenon and hypothermia } \\
\text { reduces brain infarction significantly [71]. }\end{array}$ \\
\hline $\begin{array}{l}\text { Ma et al, } 2006 \\
\text { Luo et al, } 2008\end{array}$ & Neuronatal damage due to OGD & $\begin{array}{l}\text { Combination of } 20 \% \text { Xenon and } \\
0.75 \% \text { sevoflurane preconditioning }\end{array}$ & $\begin{array}{l}\text { Combination of Xenon and sevoflurane preconditioning induces } \\
\text { long term neuroprotection by enhanced phosphorylated cyclic adenosine } \\
\text { monophosphate response element binding protection signaling. [53,55] }\end{array}$ \\
\hline
\end{tabular}

In oxygen glucose deprivation induced neuronal damage and middle cerebral artery occlusion in mice models, both Xenon preconditioning and its co-administration with insult grant neuroprotection. Combinations of Xenon with hypothermia in neonatal hypoxia-ischemia model and with sevoflurane in oxygen glucose deprivation induced neuronal damage model also enhance neuroprotection 
result of these favoring characteristics, clinical usage of Xenon for neuroprotection was approved in Europe in 2007 [50,51].

Focal cerebral ischemia, in which a blood clot occludes blood vessels of the brain [52], is commonly induced by in-vivo animal model called filament occlusion of middle cerebral artery [45]. It has been indicated that application of Xenon during MCAO in mice reduces total infarct size and augments neurologic outcome [18,19,45]. Besides its co-administration with the injury, its preconditioning also provides neuroprotection in mice model of MCAO [53].

\section{In-vitro studies}

Oxygen glucose deprivation (OGD), which is one of the in vitro models of ischemia, is a condition that neurons undergo when cerebral blood flow is disrupted. This deprivation activates excitoxicity in which NMDA glutamate receptors are over stimulated, leading to neuronal death through apoptosis and necrosis [18]. It has been shown that Xenon reduces neuronal injury by its administration before and during the insult [20,44,54]. Bantel et al. demonstrated neuronal preconditioning property of Xenon by exposing neuronal-glial co-cultures to $75 \%$ Xenon for 2 hours [55] as illustrated in Table 1. Another study that was held by Maleeha et al. showed that Xenon preconditioning protects human kidney cells from OGD injury. They proposed the mechanism in which survival factors p-Akt, HIF-1a and Bcl-2 are upregulated [20].

Xenon also acts as a neuroprotectant when coadministered with OGD injurious agents. It has been shown that Xenon reduces OGD induced neuronal cell death in mouse neuronal-glial cell co-culture at subanesthetic concentrations. Since lactate dehydrogenase release is an indication for cell injury, Xenon's mentioned neuroprotective role has been assessed by the reduction in lactate dehydrogenase release $[1,54]$. Helene et al. also proved that Xenon reduces lactate dehydrogenase and dopamine release, which is a key event in excitotoxicity in OGD [18]. This again shows that Xenon attenuates neuronal injury when it is coadministered with OGD.

\section{Combination therapy studies}

Currently, hypothermia is the only intervention that provides neuroprotection after hypoxia-ischemia [37,56-58]. It has been proven that it enhances neurological outcome after hypoxia-ischemia not only in neonatal rats, pigs, and sheep but also in infants who suffer from hypoxic ischemic encephalopathy [14] and adults after out-of-hospital CA [59]. Hypothermia makes it possible for one in six infants with neonatal encephalopathy to have reduced neurological deficits $[58,59]$. In order to increase this ratio, drugs which are able to enhance hypothermia's neuroprotection should be investigated. Xenon is a promising candidate for this role because of its lack of chemical reactivity, lack of side effects, non-fetotoxicity, and easy reversibility [37].

Studies have shown that Xenon augments neuroprotection when combined with hypothermia in animal hypoxiaischemia models $[43,60]$. Hobbs et al. have demonstrated that a combination therapy of hypothermia $\left(32^{\circ} \mathrm{C}\right)$ with inhalation of $50 \%$ Xenon for 3 hours increases neuroprotection from $37 \%$ (hypothermia only) to $76 \%$ (hypothermia combined with xenon inhalation) [60,61]. The synergistic neuroprotective effect of this treatment is still obtained even after asynchronous administration of Xenon and hypothermia. When Xenon $(20 \%)$ and hypothermia $\left(35^{\circ} \mathrm{C}\right)$ were applied asynchronously with 1 hour and 5 hours gap in between the treatments, their neuroprotective effect combined synergistically and brain infarction in neonatal rat hypoxia-ischemia model was reduced significantly [62].

Hypothermia decreases the release of glutamate that binds to NMDA receptors. It also reduces the release of glycine which assists glutamate to act on the NMDA receptor. Since Xenon is a NMDA receptor antagonist, hypothermia's role of decreasing neurotransmitter and Xenon's role of receptor blockage converge on an antiapoptotic pathway [61]. This mechanism might also explain why asynchronous administration of Xenon and hypothermia still improves the neurologic outcome of hypoxia-ischemia [14].

It has also been studied whether a combination therapy of Xenon with other drugs like dexmedetomidine and sevoflurane is effective against hypoxia-ischemia. Combination of Xenon with dexmedetomidine reduces OGD induced brain infarction in vivo [63]. Also, OGD injury is decreased in vivo by independent preconditioning of Xenon and sevoflurane $[44,46]$. Yan et al. have shown that combination of Xenon and sevoflurane preconditioning induces long term neuroprotection in neonatal asphyxia. This combination gives the chance to apply Xenon in lower doses, thus to decrease its high cost [46].

\section{Mechanism of action}

Xenon is an NMDA receptor antagonist [41]. It competitively binds to the same site as NMDA receptor coagonist glycine [64] by interacting with the aromatic ring of phenylalanine 758 [65]. Inhibition of NMDA receptors by this binding enables Xenon to perform its anesthetic and neuroprotective roles $[41,64]$.

NMDA receptor is an ionotropic receptor that is activated by binding of glutamate [66]. Although glutamate is the main excitatory neurotransmitter of central nervous system, its excessive or constant activation of NMDA receptor causes neuronal death after ischemia or stroke due to increase in cytoplasmic calcium concentration [66-70]. 
Influx of calcium through the stimulated NMDA receptor increases the nitric oxide (NO) production and cell membrane lipid peroxidation. NO, a free radical, is a potent vasodilator and is synthesized by NO synthase in endothelial cells and neurons in response to rise in intracellular calcium. Excessive generation of $\mathrm{NO}$ causes mitochondrial dysfunction. $\mathrm{NO}$ and superoxide $\left(\mathrm{O}_{2}^{-}\right)$react, resulting in large amounts of peroxynitrite $\left(\mathrm{ONOO}^{-}\right)$generation. Peroxynitrite causes DNA damage via oxidative reactions [71]. Additionally, increased calcium concentration results in activation of calpain, which in turn activates p38 (pro-death kinase), activation of stressinduced protein kinase (such as p38 and JNKs) and aggregation of proteins and nucleic acids that deteriorates lipid bilayer membrane [72] resulting in cell death. Xenon blocks NMDA receptor at the glycine binding site [73] and inhibits these excitotoxic pathways, thus establishes neuroprotection [74].

In addition, Xenon, like general anesthetics, is known to produce hypothermic effect which is also neuroprotective [74]. Hypothermia reduces excitotoxicity by decreasing glutamate and glycine release [61] and interfering with formation of reactive oxygen species [75].

\section{Anesthesia}

The use of modern anesthesia was introduced by Dr. William Morton in 1846 [76] during a dental surgery with inhalation of ether and the word 'anesthesia' was introduced by Dr. Oliver Wendell Holmes in the same year [77]. In general anesthesia, most preferred drugs are volatile anesthetics which are structurally related to ethers. These molecules are relatively more soluble in lipids than in water, so it is believed that their primary site of action is membrane proteins of nerve cells [78]. Recently there has been a renewed interest in one of the noble gases, Xenon, because of its cardio protective profile. On controversy to halogenated ethers, Xenon anesthesia has no harm on cardiovascular system furthermore it has a neuroprotective effect [79]. Yet there is still limitation in its widespread application due to its highly costs.

Although Xenon was declared to be a possible anesthetizing agent in 1939 by Albert R. Behnke Jr, it took 7 more years to be proven that Xenon has anesthetic properties by the publication of John H. Lawrence [80]. Five years had passed after the first publication to be used in a human surgery that was accomplished by American anesthesiologists Stuart C. Cullen in 1951 $[45,80]$. Till 1990s, Xenon was not a gas which was intensively researched on [81]. However, in last decades the popularity of Xenon increased due to its harmless and beneficial profile. Russia was the first country to approve the application of Xenon in anesthesia in 2000. Germany was the next country to authorize in 2005. In
2007, the approval for the usage of Xenon as an anesthetic agent was extended to all Europe [80,82].

Xenon is claimed to be an ideal anesthetic due to its unique properties $[19,81,82]$. It was observed that patients receiving Xenon anesthesia have a shorter recovery time and reduced post-operative pain [81] when compared to patients exposed to other volatile anesthetics [19]. The reason underneath is Xenon's low blood-gas partition coefficient [83].

It was also proven that Xenon doesn't have any side effects to human body $[81,84,85]$. It has been shown in vitro that Xenon doesn't cause any coagulation [86] or platelet dysfunction [87] and it doesn't deteriorate hepatic or renal functions $[88,89]$. Besides its organoprotective property, it demonstrates a low blood-gas partition coefficient of 0.115 and fast diffusion rate through blood brain barrier which enables Xenon to be both inducted and washed out in a short amount of time [13]. Xenon has further advantages like preferred hemodynamic stability [80] and rapid perfusion to specific organs [16]. As a result, Xenon is correlated with maintaining a slower heart rate and a greater arterial pressure value than other anesthetics [90]. This adventitious cardiovascular profile enables the usage of Xenon as an anesthetic agent during the operations on patients having coronary artery disease with tachycardia and low arterial pressure that are life threatening for them [91].

Other than being non-hazardous to cardiovascular system, Xenon can be also used as an anesthetic agent because of its additional neuroprotective role $[41,92]$. Most general anesthetics induce anesthesia by potentiation of gamma-amino butyric acid receptor which is an inhibitory synaptic receptor [77]. Xenon, on the other hand performs its anesthetic role by blocking NMDA receptor similar to its neuroprotective mechanism [1,41]. This blockage inhibits excitatory neurotransmission of NMDA receptors, thus causes anesthesia. Franks et al. proved that $80 \%$ Xenon decreased NMDA-activated currents by approximately $60 \%$. Xenon's blockage of NMDA receptors enables it to have anesthetic effects, since NMDA receptors are involved in synaptic mechanisms of perception of pain, learning and memory [41]. It is claimed that Xenon induces anesthesia also by activating two pore domain background potassium channel TREK-1 [19]. Once activated, these channels cause neuronal hyperpolarization. Consequently, cellular excitability is decreased and anesthesia is provided [93,94].

Besides NMDA receptor, the other two glutamate receptors are $\alpha$-amino-3-hydroxy-5-methyl-4-isoxazolole propionate (AMPA) receptor and kainate receptor which are also called as "non-NMDA receptors". Since the structures of these three glutamate receptors are very similar to each other, whether AMPA and kainate receptors are additional molecular targets for Xenon has been investigated [39]. 
Most studies confirm that Xenon causes anesthesia by inhibiting NMDA receptors, whereas the studies on its effects on AMPA and kainate receptors are contradictory [95]. In a study performed by Plested et al., AMPA receptor was expressed in Xenopus oocytes and HEK-293 cells. Its sensitivity to Xenon and how it was affected by desensitization was observed by bath application of Xenon and the recording of the resulting ionic currents. When kainate was used as an artificial agonist, Xenon blocked AMPA receptor due to desensitizing response elicited by kainate. In the second part of the study, glutamate which is a natural agonist of AMPA receptor was used rather than kainate by an ultra-rapid application system which mimicked the rapid release of high-concentration glutamate at synapses. This time Xenon didn't block AMPA receptor due to lack of desensitization. Therefore, it was concluded that the sensitivity of AMPA receptor to Xenon depended on desensitization and that AMPA receptor was not blocked during anesthesia with Xenon [96].

Dinse et al., on the other hand, demonstrated by using voltage-clamped cortical neurons from embryonic mice that desensitization still occurred with the fast application of glutamate. Xenon blocked AMPA and kainate receptors even when glutamate was used as the agonist, so it was concluded that the blockage of AMPA and kainate receptors in cortical neurons contributed to Xenon's anesthetic property [39]. Georgiev et al. agreed that Xenon performed its anesthetic action by blocking both NMDA and AMPA receptors but they claimed that this blockage occurred in spinal cord dorsal horn neurons rather than cortical neurons [95]. When these contradictory studies are examined, it is seen that the role of AMPA and kainate receptors in Xenon's anesthetic action is not as clear as the role of NMDA receptor [39]. Therefore, further investigations are needed for enriching Xenon's anesthetic mechanisms.

\section{Use of xenon in optics}

In the field of optics, noble gas Xenon is used for various purposes. After its discovery, Xenon was used in flash lamps for the first time for photography [97]. Today the majority of cameras still use Xenon gas in modern flash technology. Many of the gas-discharge lamps that we use in our daily lives like car bulbs and ceiling lights contain Xenon for energy-efficient illumination as well.

Xenon compounds are also used commonly in modern laser technology. Excimer lasers that are used for photolithography and laser eye surgery contain Xenon gas [98]. Under appropriate conditions of high pressure and electrical stimuli, Xenon gives rise to laser light in ultraviolet range by forming a compound with other excitable molecules. This relatively cheap but easy method makes it possible to selectively remove micrometer size films for producing computer chips and provide treatment to people who suffer from myopia, hyperopia and astigmatism [99].

Since Xenon flash lamps have an emission spectrum ranging from ultraviolet to infrared light, these lamps are also used in food industry and dermatological practices. In food industry, Xenon flash lamps are designed in a way that they provide high power pulses of light for killing microorganisms including bacteria, yeasts, molds and viruses [100-102]. This treatment is approved by Food and Drug Administration (FDA) in United States since it is an effective thermal treatment for food decontamination. In dermatologic practices, intense pulsed light is used for removal of hair and photo-rejuvenation [103]. Once applied to skin, light beams at a specific wavelength will target bulbs of hair where melanin pigments are abundant. The heat generated by the absorbed light will vaporize hair bulbs, which will lead to hair reduction in skin. The same principle also applies for removal of skin lesions. By using specific wavelengths and intensity of light, photo-rejuvenation therapies can remove pigmented lesions [104]. This is achieved by harnessing the efficacy of monochromatic excimer light [105].

\section{Medical imaging}

With the last technological advancements in nuclear medicine; different methods were developed in recent years aiming for better results. The idea of using Xenon gas was introduced lately in computed tomography (CT) - imaging as well as single-photon emission computed tomography (SPECT) since it has some advantages over other techniques that are currently being used [106].

Xenon enhanced CT scanning is an easy and noninvasive method in which patients inhale the stable $\left({ }^{131} \mathrm{Xe}\right)$ gas while CT images are made. It can be used for various findings like measuring cerebral blood flow after a traumatic brain injury. When clinical urgency of a traumatic patient is considered, Xenon enhanced CT is a fast and reliable procedure since less than 15 minutes of gas inhalation is required for the process. In this method, non-radioactive molecule Xenon $\left({ }^{131} \mathrm{Xe}\right)$ is used as a contrast agent [107], for getting good resolution images [108]. It is non- hazardous for the body since half-life of

${ }^{131}$ Xenon is about 40 seconds in cerebral tissue so it is washed away rapidly after inhalation [109]. Once inhaled, diffusion rate of the gas into tissue would indicate the amount of blood flow that area is receiving, so that further clinical examinations can be administered. This technique is also used for measuring tissue blood flow in pancreatic tumors [110].

In SPECT, radioactive isotope $\left({ }^{133} \mathrm{Xe}\right)$ of Xenon is used as radionuclide. Since Xenon is a small inert molecule, soluble in lipid and water, readily exchanged between blood and tissue, and diffusible in the brain, it is 
considered as a good agent for SPECT [105]. This technique can be used for obtaining quantitative and repeatable whole-brain scans [111], ventilation studies of lungs, measurement of cerebral blood flow [107] to study pathology of dementia, Alzheimer's disease, epilepsy, obsessive-compulsive disorders [112].

\section{Toxicity}

Volatile and inhalation anesthetics are dangerous for ozone layer because of their chlorofluorocarbon based structures [19]. One of the inhalational agents, nitrous oxide, is 230 times more potent as a greenhouse gas when compared with carbon dioxide [113]. On contrary, Xenon has no undesirable ecological effects since it is a naturally occurring gas in Earth's atmosphere.

Xenon is a good candidate for being an ideal anesthetic not only because of its beneficial effects, but also its lack of toxicity. Besides being non-neurotoxic, Xenon doesn't have any effect on hematological and biochemical variables as well [88]. It has been shown that Xenon has no impact on coagulation/platelet function [87], nor on immune system [114]. Xenon is non-reactive in the body, it is disposed from the lungs without interfering with hepatic and renal systems, thus it doesn't impair hepatic or renal function $[88,89]$.

\section{Cost-efficiency}

Xenon is a trace element in Earth's atmosphere [60], expense of its fractional distillation is very high and it cannot be industrially synthesized [50]. Therefore, Xenon is relatively more expensive than other anesthetic and neuroprotective agents [115]. Xenon's scarcity and high cost (10 $\$ / \mathrm{L}$ ) [85] are major handicaps along the way of being used commonly as an ideal anesthetic and neuroprotectant [60]. While other volatile anesthetics have a cost around $10 \$$ for 2 hours of administration, Xenon's expense for the same time interval is $300 \$$ in total [90]. Consequently, cheaper methods should be investigated to use Xenon more efficiently and economically. A closed-circulatory system is recently developed for this scope [18], enabling the reuse of Xenon gas and mechanical replenishment of oxygen [61]. On the other hand, the high cost of Xenon might not be as great as it seems, since Xenon anesthesia improves clinical outcome. Reduced hospital stay duration and decreased need of post-operative intensive care might outweigh the cost of Xenon [90]. It seems further studies are necessary to evaluate cost effectiveness of Xenon in clinical usage.

\section{Conclusion and further studies}

Xenon has a bright future in medicine due to its noticeable advantages over other anesthetic agents. Despite of its highly costs, its neuro and myocardio protective profile, non-toxic chemical properties, nature friendly feature and efficacy in hypoxia-ischemia treatment combined with hypothermia makes it an ideal candidate for innovations in medical gas field. Promising findings obtained from in vivo-vitro studies of xenon denote that xenon will take its part in neuroprotective treatments for brain trauma, resuscitation and ischemic insults. However, further research and large-scale investigations are necessary for utilizing Xenon's therapeutic potential maximally. The highly cost of Xenon should also be overcome for achieving this goal.

\section{Abbreviations}

HI: Hypoxic-ischemic injury; MCAO: Middle Cerebral Artery Occlusion; FDA: Food and Drug Administration; CA: Cardiac Arrest; NMDA: N-methyl-Daspartate; OGD: Oxygen glucose deprivation; NO: Nitric Oxide;

$\mathrm{O}_{2}$ : Superoxide; ONOO: Peroxynitrite; AMPA: a -amino-3-hydroxy-5-methyl-4isoxazolole propionate; CT: Computed Tomography; SPECT: Single-photon emission computed tomography.

\section{Competing interests}

The authors declare that they have no competing interests.

\section{Authors' contributions}

$E E, S Y, Y B$, and AR identified the subject, did literature search and wrote the initial draft, IS revised the manuscript, JHZ helped to identify the subject and revised the manuscript. All authors read and approved the final manuscript.

\section{Author details}

${ }^{1}$ Koc University School of Medicine, Rumelifeneri Yolu, Sariyer-Istanbul 34450, Turkey. ${ }^{2}$ Université Lorraine Faculté de Médecine, 9 Avenue de la Forét de Haye, Vandoeuvre-lés-Nancy 54505, France. ${ }^{3}$ Departments of Neurosurgery and Physiology, Loma Linda University, Loma Linda, CA, USA.

Received: 7 November 2012 Accepted: 25 January 2013

Published: 1 February 2013

\section{References}

1. Liu W, Khatibi N, Sridharan A, Zhang JH: Application of medical gases in the field of neurobiology. Med Gas Res 2011, 1:13.

2. Christl SU, Murgatroyd PR, Gibson GR, Cummings JH: Production, metabolism, and excretion of hydrogen in the large intestine. Gastroenterology 1992, 102:1269-1277.

3. Hammer HF: Colonic hydrogen absorption: quantification of its effect on hydrogen accumulation caused by bacterial fermentation of carbohydrates. Gut 1993, 34:818-822

4. Ohsawa I, Ishikawa M, Takahashi K, Watanabe M, Nishimaki K, Yamagata K, Katsura K-I, Katayama Y, Asoh S, Ohta S: Hydrogen acts as a therapeutic antioxidant by selectively reducing cytotoxic oxygen radicals. Nat Med 2007, 13:688-694.

5. Cai J, Kang Z, Liu WW, Luo X, Qiang S, Zhang JH, Ohta S, Sun X, Xu W, Tao H, Li R: Hydrogen therapy reduces apoptosis in neonatal hypoxia-ischemia rat model. Neurosci Lett 2008, 441:167-172.

6. Cai J, Kang Z, Liu K, Liu W, Li R, Zhang JH, Luo X, Sun X: Neuroprotective effects of hydrogen saline in neonatal hypoxia-ischemia rat model. Brain Res 2009, 1256:129-137.

7. Domoki F, Oláh O, Zimmermann A, Németh I, Tóth-Szuki V, Hugyecz M, Temesvári $P$, Bari F: Hydrogen is neuroprotective and preserves cerebrovascular reactivity in asphyxiated newborn pigs. Pediatr Res 2010, 68:387-392.

8. Heinen A, Huhn R, Smeele KMA, Zuurbier CJ, Schlack W, Preckel B, Weber NC, Hollmann MW: Helium-induced preconditioning in young and old rat heart: impact of mitochondrial $\mathrm{Ca}(2+)$-sensitive potassium channel activation. Anesthesiology 2008, 109:830-836.

9. Pagel PS, Krolikowski JG, Pratt PF Jr, Shim YH, Amour J, Warltier DC, Weihrauch D: Reactive oxygen species and mitochondrial adenosine triphosphate-regulated potassium channels mediate helium-induced preconditioning against myocardial infarction in vivo. J Cardiothorac Vasc Anesth 2008, 22:554-559. 
10. Pagel PS, Krolikowski JG, Pratt PF Jr, Shim YH, Amour J, Warltier DC, Weihrauch D: The mechanism of helium-induced preconditioning: a direct role for nitric oxide in rabbits. Anesth Analg 2008, 107:762-768.

11. Buras JA, Stahl GL, Svoboda KK, Reenstra WR: Hyperbaric oxygen downregulates ICAM-1 expression induced by hypoxia and hypoglycemia: the role of NOS. Am J Physiol Cell Physiol 2000, 278:C292C302.

12. Jawad N, Rizvi M, Gu J, Adeyi O, Tao G, Maze M, Ma D: Neuroprotection (and lack of neuroprotection) afforded by a series of noble gases in an in vitro model of neuronal injury. Neurosci Lett 2009, 460:232-236.

13. Nakao A, Sugimoto R, Billiar TR, McCurry KR: Therapeutic antioxidant medical gas. J Clin Biochem Nutr 2009, 44:1-13.

14. Kelen D, Robertson NJ: Experimental treatments for hypoxic ischaemic encephalopathy. Early Hum Dev 2010, 86:369-377.

15. Joyce JA: Xenon: anesthesia for the 21st century. AANA J 2000 68:259-264

16. Marx T, Schmidt M, Schirmer U, Reinelt H: Xenon anaesthesia. J R Soc Med 2000, 93:513-517.

17. Dworschak M: Pharmacologic neuroprotection-is xenon the light at the end of the tunnel? Crit Care Med 2008, 36:2477-2479.

18. David HN, Haelewyn B, Rouillon C, Lecoq M, Chazalviel L, Apiou G, Risso J-J, Lemaire M, Abraini JH: Neuroprotective effects of xenon: a therapeutic window of opportunity in rats subjected to transient cerebral ischemia. FASEB J 2008, 22:1275-1286.

19. Sanders RD, Maze M: Xenon: from stranger to guardian. Curr Opin Anaesthesiol 2005, 18:405-411.

20. Rizvi M, Jawad N, Li Y, Vizcaychipi MP, Maze M, Ma D: Effect of noble gases on oxygen and glucose deprived injury in human tubular kidney cells. Exp Biol Med (Maywood) 2010, 235:886-891.

21. Lane GA, Nahrwold ML, Tait AR, Taylor-Busch M, Cohen PJ, Beaudoin AR: Anesthetics as teratogens: nitrous oxide is fetotoxic, xenon is not. Science 1980, 210:899-901.

22. Preckel B, Weber NC, Sanders RD, Maze M, Schlack W: Molecular mechanisms transducing the anesthetic, analgesic, and organ-protective actions of xenon. Anesthesiology 2006, 105:187-197.

23. de Vreede-Swagemakers JJ, Gorgels AP, Dubois-Arbouw WI, van Ree JW, Daemen MJ, Houben LG, Wellens HJ: Out-of-hospital cardiac arrest in the 1990's: a population-based study in the Maastricht area on incidence, characteristics and survival. J Am Coll Cardiol 1997, 30:1500-1505.

24. Zheng ZJ, Croft JB, Giles WH, Mensah GA: Sudden cardiac death in the United States, 1989 to 1998. Circulation 2001, 104:2158-2163.

25. Stiell IG, Wells GA, Field B, Spaite DW, Nesbitt LP, De Maio VJ, Nichol G, Cousineau D, Blackburn J, Munkley D, Luinstra-Toohey L, Campeau T, Dagnone E, Lyver M: Advanced cardiac life support in out-of-hospital cardiac arrest. N Engl J Med 2004, 351:647-656.

26. Hallstrom AP, Ornato JP, Weisfeldt M, Travers A, Christenson J, McBurnie MA Zalenski R, Becker LB, Schron EB, Proschan M: Public-access defibrillation and survival after out-of-hospital cardiac arrest. N Engl J Med 2004, 351:637-646.

27. Engdahl J, Bång A, Lindqvist J, Herlitz J: Time trends in long-term mortality after out-of-hospital cardiac arrest, 1980 to 1998, and predictors for death. Am Heart J 2003, 145:826-833.

28. Nichol G, Stiell IG, Laupacis A, Pham B, De Maio VJ, Wells GA: A cumulative meta-analysis of the effectiveness of defibrillator-capable emergency medical services for victims of out-of-hospital cardiac arrest. Ann Emerg Med 1999, 34:517-525.

29. Hossmann KA: Reperfusion of the brain after global ischemia: hemodynamic disturbances. Shock 1997, 8:95-101. discussion 102-103.

30. Radovsky A, Safar P, Sterz F, Leonov Y, Reich H, Kuboyama K: Regional prevalence and distribution of ischemic neurons in dog brains 96 hours after cardiac arrest of 0 to 20 minutes. Stroke 1995, 26:2127-2133. discussion 2133-2134.

31. Ouyang YB, Tan Y, Comb M, Liu CL, Martone ME, Siesjö BK, Hu BR: Survivaland death-promoting events after transient cerebral ischemia: phosphorylation of Akt, release of cytochrome $C$ and activation of caspase-like proteases. J Cereb Blood Flow Metab 1999, 19:1126-1135.

32. Rockwood K, Brown M, Merry H, Sketris I, Fisk J: Societal costs of vascular cognitive impairment in older adults. Stroke 2002, 33:1605-1609.

33. Hopkins $\mathrm{RO}$, Jackson JC: Long-term neurocognitive function after critical illness. Chest 2006, 130:869-878.
34. Zola-Morgan S, Squire LR, Rempel NL, Clower RP, Amaral DG: Enduring memory impairment in monkeys after ischemic damage to the hippocampus. J Neurosci 1992, 12:2582-2596.

35. Rempel-Clower NL, Zola SM, Squire LR, Amaral DG: Three cases of enduring memory impairment after bilateral damage limited to the hippocampal formation. J Neurosci 1996, 16:5233-5255.

36. Fries M, Nolte KW, Coburn M, Rex S, Timper A, Kottmann K, Siepmann K, Häusler M, Weis J, Rossaint R: Xenon reduces neurohistopathological damage and improves the early neurological deficit after cardiac arrest in pigs. Crit Care Med 2008, 36:2420-2426.

37. Chakkarapani E, Thoresen M, Hobbs CE, Aquilina K, Liu X, Dingley J: A closed-circuit neonatal xenon delivery system: a technical and practical neuroprotection feasibility study in newborn pigs. Anesth Analg 2009, 109:451-460

38. Parsons MW, Li T, Barber PA, Yang Q, Darby DG, Desmond PM, Gerraty RP, Tress BM, Davis SM: Combined (1)H MR spectroscopy and diffusionweighted MRI improves the prediction of stroke outcome. Neurology 2000, 55:498-505.

39. Dinse A, Föhr KJ, Georgieff M, Beyer C, Bulling A, Weigt HU: Xenon reduces glutamate-, AMPA-, and kainate-induced membrane currents in cortical neurones. Br J Anaesth 2005, 94:479-485.

40. Natale G, Cattano D, Abramo A, Forfori F, Fulceri F, Fornai F, Paparelli A, Giunta F: Morphological evidence that xenon neuroprotects against $\mathrm{N}$-methyl-DL-aspartic acid-induced damage in the rat arcuate nucleus: a time-dependent study. Ann N Y Acad Sci 2006, 1074:650-658.

41. Franks NP, Dickinson R, de Sousa SLM, Hall AC, Lieb WR: How does xenon produce anaesthesia? Nature 1998, 396:324-324.

42. Hardingham GE, Bading $H$ : The Yin and Yang of NMDA receptor signalling. Trends Neurosci 2003, 26:81-89.

43. Dingley J, Tooley J, Porter H, Thoresen M: Xenon provides short-term neuroprotection in neonatal rats when administered after hypoxiaischemia. Stroke 2006, 37:501-506.

44. Ma D, Hossain M, Pettet GKJ, Luo Y, Lim T, Akimov S, Sanders RD, Franks NP, Maze $\mathrm{M}$ : Xenon preconditioning reduces brain damage from neonatal asphyxia in rats. J Cereb Blood Flow Metab 2006, 26:199-208.

45. Homi HM, Yokoo N, Ma D, Warner DS, Franks NP, Maze M, Grocott HP: The neuroprotective effect of xenon administration during transient middle cerebral artery occlusion in mice. Anesthesiology 2003, 99:876-881.

46. Luo Y, Ma D, leong E, Sanders RD, Yu B, Hossain M, Maze M: Xenon and sevoflurane protect against brain injury in a neonatal asphyxia model. Anesthesiology 2008, 109:782-789.

47. Coburn M, Kunitz O, Baumert J-H, Hecker K, Haaf S, Zühlsdorff A, Beeker T, Rossaint R: Randomized controlled trial of the haemodynamic and recovery effects of xenon or propofol anaesthesia. Br J Anaesth 2005, 94:198-202.

48. Preckel B, Schlack W, Heibel T, Rütten H: Xenon produces minimal haemodynamic effects in rabbits with chronically compromised left ventricular function. $\mathrm{Br} J$ Anaesth 2002, 88:264-269.

49. Goto T, Saito H, Shinkai M, Nakata Y, Ichinose F, Morita S: Xenon provides faster emergence from anesthesia than does nitrous oxide-sevoflurane or nitrous oxide-isoflurane. Anesthesiology 1997, 86:1273-1278.

50. Spieth PM, Parotto M: Xenon and the developing brain. Minerva Anestesiol 2011, 77:565-566

51. Derwall M, Coburn M, Rex S, Hein M, Rossaint R, Fries M: Xenon: recent developments and future perspectives. Minerva Anestesiol 2009, 75:37-45.

52. Smith WS: Pathophysiology of focal cerebral ischemia: a therapeutic perspective. J Vasc Interv Radiol 2004, 15:S3-S12.

53. Horiguchi T, Snipes JA, Kis B, Shimizu K, Busija DW: Cyclooxygenase-2 mediates the development of cortical spreading depression-induced tolerance to transient focal cerebral ischemia in rats. Neuroscience 2006 140:723-730.

54. Wilhelm S, Ma D, Maze M, Franks NP: Effects of xenon on in vitro and in vivo models of neuronal injury. Anesthesiology 2002, 96:1485-1491.

55. Bantel C, Maze M, Trapp S: Neuronal preconditioning by inhalational anesthetics. Anesthesiology 2009, 110:986-995

56. Tooley JR, Satas S, Porter H, Silver IA, Thoresen M: Head cooling with mild systemic hypothermia in anesthetized piglets is neuroprotective. Ann Neurol 2003, 53:65-72

57. Gunn AJ, Thoresen M: Hypothermic neuroprotection. NeuroRx 2006, 3:154-169 
58. Gluckman PD, Wyatt JS, Azzopardi D, Ballard R, Edwards AD, Ferriero DM, Polin RA, Robertson CM, Thoresen M, Whitelaw A, Gunn AJ: Selective head cooling with mild systemic hypothermia after neonatal encephalopathy: multicentre randomised trial. Lancet 2005, 365:663-670.

59. Thoresen M, Hobbs CE, Wood T, Chakkarapani E, Dingley J: Cooling combined with immediate or delayed xenon inhalation provides equivalent long-term neuroprotection after neonatal hypoxia-ischemia. J Cereb Blood Flow Metab 2009, 29:707-714.

60. Chakkarapani E, Dingley J, Liu X, Hoque N, Aquilina K, Porter H, Thoresen M: Xenon enhances hypothermic neuroprotection in asphyxiated newborn pigs. Ann Neurol 2010, 68:330-341.

61. Hobbs C, Thoresen M, Tucker A, Aquilina K, Chakkarapani E, Dingley J: Xenon and hypothermia combine additively, offering long-term functional and histopathologic neuroprotection after neonatal hypoxia/ ischemia. Stroke 2008, 39:1307-1313.

62. Martin JL, Ma D, Hossain M, Xu J, Sanders RD, Franks NP, Maze M: Asynchronous administration of xenon and hypothermia significantly reduces brain infarction in the neonatal rat. Br J Anaesth 2007, 98:236-240.

63. Rajakumaraswamy N, Ma D, Hossain M, Sanders RD, Franks NP, Maze M: Neuroprotective interaction produced by xenon and dexmedetomidine on in vitro and in vivo neuronal injury models. Neurosci Lett 2006, 409:128-133.

64. Dickinson R, Peterson BK, Banks P, Simillis C, Martin JCS, Valenzuela CA Maze M, Franks NP: Competitive inhibition at the glycine site of the $\mathrm{N}$-methyl-d-aspartate receptor by the anesthetics xenon and isoflurane. Anesthesiology 2007, 107:756-767.

65. Armstrong SP, Banks PJ, McKitrick TJW, Geldart CH, Edge CJ, Babla R, Simillis C, Franks NP, Dickinson R: Identification of Two mutations (F758W and F758Y) in the N-methyl-D-aspartate receptor glycine-binding site that selectively prevent competitive inhibition by xenon without affecting glycine binding. Anesthesiology 2012, 117:38-47.

66. Li M, Inoue K, Si H, Xiong Z: Calcium-permeable ion channels involved in glutamate receptor-independent ischemic brain injury. Acta Pharmacol $\sin 2011$, 32:734-740

67. Fatokun AA, Stone TW, Smith RA: Adenosine receptor ligands protect against a combination of apoptotic and necrotic cell death in cerebellar granule neurons. Exp Brain Res 2008, 186:151-160.

68. Hardingham GE: Coupling of the NMDA receptor to neuroprotective and neurodestructive events. Biochem Soc Trans 2009, 37:1147-1160.

69. Choi DW: Calcium-mediated neurotoxicity: relationship to specific channel types and role in ischemic damage. Trends Neurosci 1988, 11:465-469.

70. Siesjö BK: Historical overview. Calcium, ischemia, and death of brain cells. Ann N Y Acad Sci 1988, 522:638-661.

71. Solaroglu I, Solaroglu A, Kaptanoglu E, Dede S, Haberal A, Beskonakli E, Kilinc K: Erythropoietin prevents ischemia-reperfusion from inducing oxidative damage in fetal rat brain. Childs Nerv Syst 2003, 19:19-22.

72. Verkhratsky A, Rodríguez JJ, Parpura V: Calcium signalling in astroglia. Mol Cell Endocrinol 2012, 353:45-56

73. Banks $P$, Franks NP, Dickinson R: Competitive inhibition at the glycine site of the N-methyl-D-aspartate receptor mediates xenon neuroprotection against hypoxia-ischemia. Anesthesiology 2010, 112:614-622.

74. Abraini $J H$, David HN, Lemaire M: Potentially neuroprotective and therapeutic properties of nitrous oxide and xenon. Ann N Y Acad Sci 2005, 1053:289-300

75. Weng $Y$, Sun S: Therapeutic hypothermia after cardiac arrest in adults: mechanism of neuroprotection, phases of hypothermia, and methods of cooling. Crit Care Clin 2012, 28:231-243.

76. Bovill JG: Inhalation anaesthesia: from diethyl ether to xenon. Handb Exp Pharmacol 2008, 182:121-142

77. How does anesthesia work?: Scientific American. http://www scientificamerican.com/article.cfm?id=how-does-anesthesia-work.

78. Franks NP, Lieb WR: Molecular and cellular mechanisms of general anaesthesia. Nature 1994, 367:607-614.

79. Baumert J-H, Hein M, Hecker KE, Satlow S, Neef P, Rossaint R: Xenon or propofol anaesthesia for patients at cardiovascular risk in non-cardiac surgery. Br J Anaesth 2008, 100:605-611.

80. Tonner PH: Xenon: one small step for anaesthesia. . . ? Curr Opin Anaesthesiol 2006, 19:382-384.

81. Kratzer S, Mattusch C, Kochs E, Eder M, Haseneder R, Rammes G: Xenon attenuates hippocampal long-term potentiation by diminishing synaptic and extrasynaptic N-methyl-D-aspartate receptor currents. Anesthesiology 2012, 116:673-682.

82. Ma D, Wilhelm S, Maze M, Franks NP: Neuroprotective and neurotoxic properties of the "inert" gas, xenon. Br J Anaesth 2002, 89:739-746.

83. Goto T, Suwa K, Uezono S, Ichinose F, Uchiyama M, Morita S: The blood-gas partition coefficient of xenon may be lower than generally accepted. $\mathrm{Br} J$ Anaesth 1998, 80:255-256.

84. Rossaint R, Reyle-Hahn M, Schulte Am Esch J, Scholz J, Scherpereel P, Vallet B, Giunta F, Del Turco M, Erdmann W, Tenbrinck R, Hammerle AF, Nagele P: Multicenter randomized comparison of the efficacy and safety of xenon and isoflurane in patients undergoing elective surgery. Anesthesiology 2003, 98:6-13.

85. Lynch C 3rd, Baum J, Tenbrinck R: Xenon anesthesia. Anesthesiology 2000, 92:865-868.

86. Horn NA, Hecker KE, Bongers B, Baumert HJ, Reyle-Hahn SM, Rossaint R: Coagulation assessment in healthy pigs undergoing single xenon anaesthesia and combinations with isoflurane and sevoflurane. Acta Anaesthesiol Scand 2001, 45:634-638.

87. de Rossi LW, Horn NA, Baumert JH, Gutensohn K, Hutschenreuter G, Rossaint $\mathrm{R}$ : Xenon does not affect human platelet function in vitro. Anesth Analg 2001, 93:635.

88. Bedi A, Murray JM, Dingley J, Stevenson MA, Fee JPH: Use of xenon as a sedative for patients receiving critical care. Crit Care Med 2003, 31:2470-2477.

89. Reinelt H, Marx T, Kotzerke J, Topalidis P, Luederwald S, Armbruster S, Schirmer U, Schmidt M: Hepatic function during xenon anesthesia in pigs. Acta Anaesthesiol Scand 2002, 46:713-716.

90. Baumert J-H: Xenon-based anesthesia: theory and practice. Open Access Surgery 2009, 2:5-13.

91. Sprung J, Abdelmalak B, Gottlieb A, Mayhew C, Hammel J, Levy PJ, O'Hara $P$, Hertzer NR: Analysis of risk factors for myocardial infarction and cardiac mortality after major vascular surgery. Anesthesiology 2000 93:129-140.

92. Schmidt M, Marx T, Glöggl E, Reinelt H, Schirmer U: Xenon attenuates cerebral damage after ischemia in pigs. Anesthesiology 2005, 102:929-936.

93. Heurteaux C, Guy N, Laigle C, Blondeau N, Duprat F, Mazzuca M, LangLazdunski L, Widmann C, Zanzouri M, Romey G, Lazdunski M: TREK-1, a $\mathrm{K}+$ channel involved in neuroprotection and general anesthesia. EMBO J 2004, 23:2684-2695.

94. Sanders RD, Ma D, Maze M: Xenon: elemental anaesthesia in clinical practice. Br Med Bull 2004, 71:115-135.

95. Georgiev SK, Furue H, Baba H, Kohno T: Xenon inhibits excitatory but not inhibitory transmission in rat spinal cord dorsal horn neurons. Mol Pain 2010, 6:25

96. Plested AJ, Wildman SS, Lieb WR, Franks NP: Determinants of the Sensitivity of AMPA Receptors to Xenon. Anesthesiology 2004, 100:347-358.

97. Burke J: Twin tracks: the unexpected origins of the modern world. New York: Simon \& Schuster; 2003.

98. Spencer JM, Hadi SM: The excimer lasers. J Drugs Dermatol 2004, 3:522-525.

99. Gauthier L: Astigmatism correction with excimer laser. J Fr Ophtalmol 2012, 35:206-211.

100. Moraru C: Pulsed light treatment to enhance food safety. [http://fshn.illinois. edu/food_processing_forum/presentations/c5_Moraru_abstract.pdf].

101. Elmnasser N, Guillou S, Leroi F, Orange N, Bakhrouf A, Federighi M: Pulsed-light system as a novel food decontamination technology: a review. Can $J$ Microbiol 2007, 53:813-821.

102. Folwaczny M, Liesenhoff T, Lehn N, Horch HH: Bactericidal action of $308 \mathrm{~nm}$ excimer-laser radiation: an in vitro investigation. J Endod 1998, 24:781-785.

103. Morita A, Weiss M, Maeda A: Recent developments in phototherapy: treatment methods and devices. Recent Pat Inflamm Allergy Drug Discov 2008, 2:105-108.

104. Mavilia L, Mori M, Rossi R, Campolmi P, Puglisi Guerra A, Lotti T: 308 nm monochromatic excimer light in dermatology: personal experience and review of the literature. G Ital Dermatol Venereol 2008, 143:329-337.

105. Nisticò SP, Saraceno R, Capriotti E, Felice CD, Chimenti S: Efficacy of monochromatic excimer light $(308 \mathrm{~nm})$ in the treatment of atopic dermatitis in adults and children. Photomed Laser Surg 2008, 26:14-18.

106. Ko NU, Achrol AS, Martin AJ, Chopra M, Saloner DA, Higashida RT, Young WL: Magnetic resonance perfusion tracks $133 \mathrm{Xe}$ cerebral blood flow changes after carotid stenting. Stroke 2005, 36:676-678.

107. Coles JP: Imaging after brain injury. Br J Anaesth 2007, 99:49-60. 
108. Latchaw RE, Yonas H, Hunter GJ, Yuh WTC, Ueda T, Sorensen AG, Sunshine JL, Biller J, Wechsler L, Higashida R, Hademenos G: Guidelines and recommendations for perfusion imaging in cerebral ischemia a scientific statement for healthcare professionals by the writing group on perfusion imaging, from the council on cardiovascular radiology of the American heart association. Stroke 2003, 34:1084.

109. Wintermark M, Sesay M, Barbier E, Borbély K, Dillon WP, Eastwood JD, Glenn TC, Grandin CB, Pedraza S, Soustiel J-F, Nariai T, Zaharchuk G, Caillé J-M, Dousset $\mathrm{V}$, Yonas $\mathrm{H}$ : Comparative overview of brain perfusion imaging techniques. Stroke 2005, 36:e83-e99.

110. Kubota M, Murakami T, Nagano H, Eguchi H, Marubashi S, Kobayashi S, Wada H, Tanemura M, Dono K, Nakamori S, Sakon M, Monden M, Mori M, Doki Y: Xenon-inhalation computed tomography for noninvasive quantitative measurement of tissue blood flow in pancreatic tumor. Dig Dis Sci 2012, 57:801-805.

111. Mountz JM, Liu HG, Deutsch G: Neuroimaging in cerebrovascular disorders: measurement of cerebral physiology after stroke and assessment of stroke recovery. Semin Nucl Med 2003, 33:56-76.

112. Saha G, Macintyre W, Go R: Radiopharmaceuticals for brain imaging. Semin Nucl Med 1994, 24:324-349.

113. Goto T: Is there a future for xenon anesthesia? Can J Anaesth 2002, 49:335-338.

114. Bedi A, McBride WT, Armstrong MA, Murray JM, Fee JPH: Xenon has no effect on cytokine balance and adhesion molecule expression within an isolated cardiopulmonary bypass system. Br J Anaesth 2002, 89:546-550.

115. Torri G: Inhalation anesthetics: a review. Minerva Anestesiol 2010, 76:215-228

doi:10.1186/2045-9912-3-4

Cite this article as: Esencan et al: XENON in medical area: emphasis on neuroprotection in hypoxia and anesthesia. Medical Gas Research 2013 3:4.

\section{Submit your next manuscript to BioMed Central and take full advantage of:}

- Convenient online submission

- Thorough peer review

- No space constraints or color figure charges

- Immediate publication on acceptance

- Inclusion in PubMed, CAS, Scopus and Google Scholar

- Research which is freely available for redistribution 